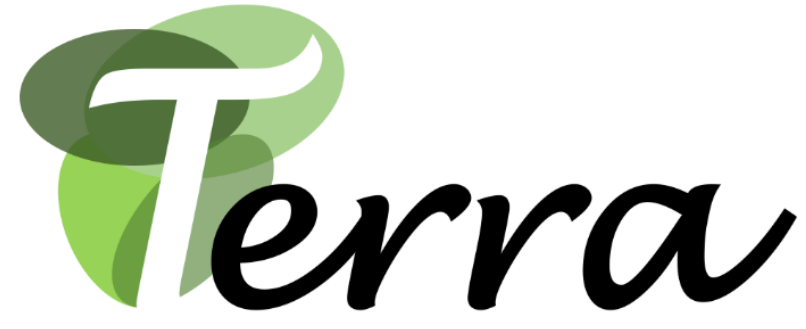

Revista de Desarrollo Local

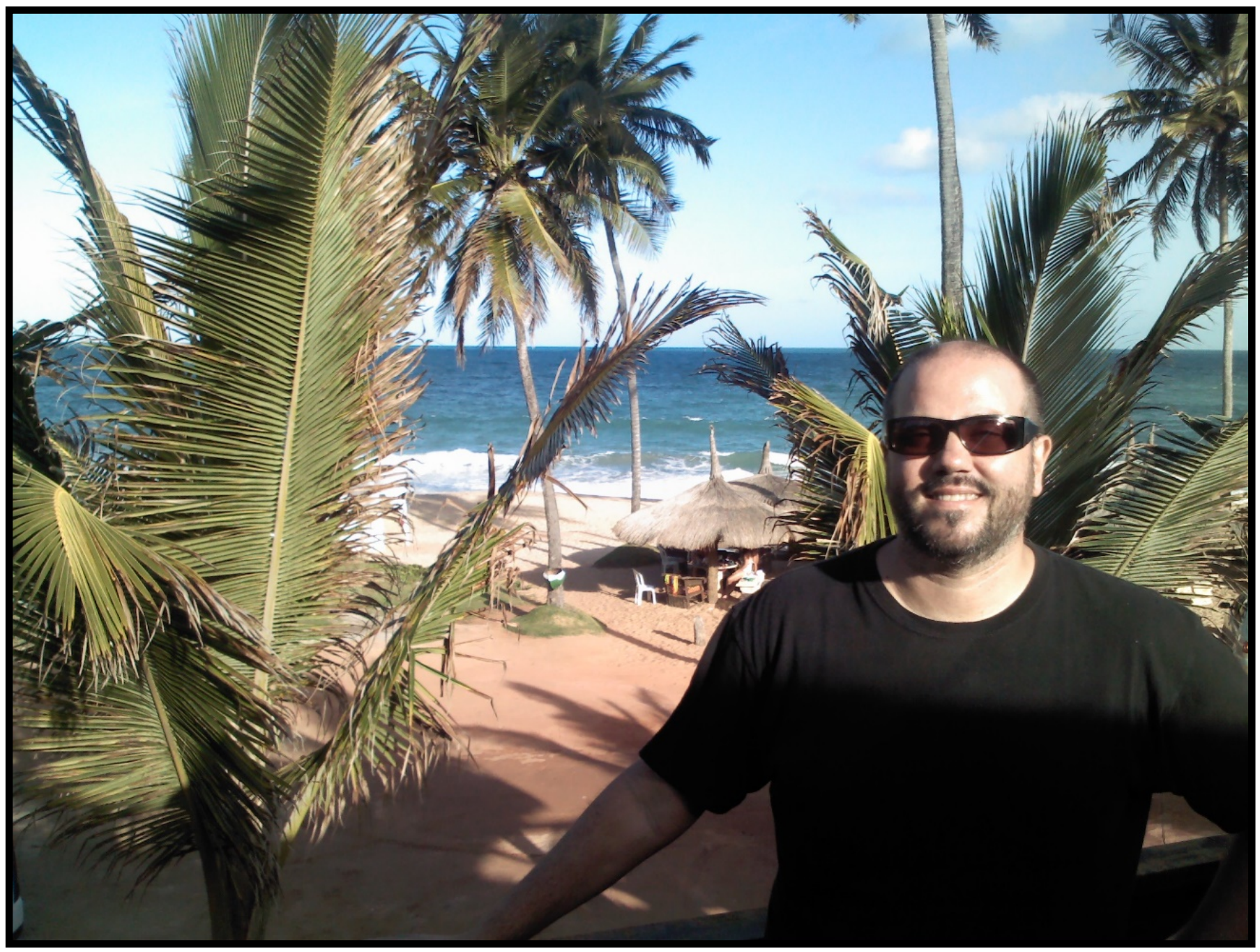

- Homenaje a Joan Noguera Tur -

\section{UNIVERSITAT}

Institut Interuniversitari

de Desenvolupament Local

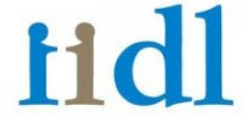

$\begin{array}{lllllll} & N & S & T & I & T & U\end{array}$ INTERUNIVERSITARI DE DESENVOLUPAMENT LOCAL

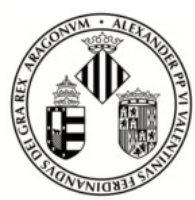

VNIVERSITAT

(E) VAlẼnCia 
TERRA. Revista de Desarrollo Local e-ISSN: 2386-9968

Número 8 (2021), 628-644

DOI 10.7203/terra.8.20365

IIDL - Instituto Interuniversitario de Desarrollo Local

\title{
Espacios de ocio para el desarrollo humano
}

\author{
Gustavo Adolfo Maldonado Martínez
}

Facultad de Filosofía y Letras, Universidad Autónoma de Chihuahua (México)

gustavo.maldonado4724@gmail.com

https://orcid.org/0000-0001-7345-5514

\section{Jaime Cuenca Amigo}

Instituto de Estudios de Ocio, Facultad de Ciencias Sociales y Humanas, Universidad de Deusto (España)

jaime.cuenca@deusto.es

https://orcid.org/0000-0001-5744-4073

\section{(C) $(1) \Theta \Theta$}

Esta obra se distribuye con la licencia Creative Commons 


\title{
SECCIÓN NOTAS Y AVANCES DE INVESTIGACIÓN
}

\author{
Espacios de ocio para el desarrollo humano
}

Resumen: El presente artículo parte de la necesidad por reflexionar en torno al impacto de la mercantilización en la valoración y producción social de los espacios para el ocio. A través de distinciones y precisiones conceptuales entre espacio, lugar y ocio, este trabajo pretende analizar dos consecuencias importantes de la mercantilización en la valoración del espacio social: la producción del espacio a través de la mercantilización produce valor mercantil. El espacio en sentido social se torna entonces en un contenedor de relaciones sociales mediadas por la mercancía, y esto es apreciable en los espacios para la ocupación del tiempo de ocio. Sin embargo, pretendemos sustentar aquí que el ocio es un posible agente de emancipación y productor de valor en otros sentidos. Los espacios también han de contener valor no necesariamente en sentido mercantil, y es ahí donde es posible un punto de encuentro con el valor del ocio y los espacios para este. Así, se persigue la idea de que el ocio puede fungir como resistencia, diferenciándose del común malentendido de situarlo como actividad ligada irremediablemente al consumo. En cambio, nos inclinamos por proponerlo como experiencia formativa capaz de potenciar las capacidades humanas por medio de su desarrollo. Se busca así plantear alternativas en torno a la posibilidad de encontrar por medio de la experiencia de ocio resquicios de emancipación y resistencia para hacer frente a la mercantilización y el consumo y proponer formas de desarrollo local que sean cauce de desarrollo humano y comunitario.

Palabras clave: Espacio, lugar, tiempo de ocio, valor, mercancía.

\section{Leisure spaces for human development}

Abstract: This article is based on the need to reflect on the impact of commodification on the valuation and social production of leisure spaces. Through conceptual distinctions and clarifications between space, place and leisure, this paper aims to analyse two important consequences of commodification on the valuation of social space: The production of space through commodification produces market value. Space in a social sense then becomes a container for commodity-mediated social relations, and this is visible in the spaces for the occupation of leisure time. However, we intend to argue here that leisure is a possible agent of emancipation and producer of value in other senses. Spaces also have to contain value not necessarily in a mercantile sense, and this is where a meeting point with the value of leisure and spaces for leisure is possible. Thus, we pursue the idea that leisure can function as resistance, as opposed to the common misunderstanding of situating it as an activity irremediably linked to consumption. Instead, we are inclined to propose it as a formative experience capable of enhancing human capacities through its development. In this way, we seek to propose alternatives around the possibility of finding, through the experience of leisure, loopholes for emancipation and resistance in order to confront commercialisation and consumption and to propose forms of local development that are a channel for human and community development.

Key words: Valuable leisure, human development, recreation, re-creation.

Recibido: 09 de noviembre de 2020

Devuelto para revisión: 23 de abril de 2021

Aceptado: 24 de mayo de 2021

Referencia / Citation:

Maldonado, G. A., y Cuenca, J. (2021). Espacios de ocio para el desarrollo humano. TERRA. Revista de Desarrollo Local, (8), 628-644. DOI 10.7203/terra.8.20365 


\title{
1. INTRODUCCIÓN: EL TIEMPO ES LOCAL ${ }^{1}$
}

Para comenzar esta reflexión sobre el valor de los espacios para el ocio, definiremos a continuación los conceptos de los que partiremos. No sin antes destacar que el presente trabajo trata de una reflexión teórica y no pretende presentar resultados empíricos. Asimismo, es relevante precisar que, la reflexión en torno al valor local (o a la localización del valor) que aquí se propone parte de muy diversas fuentes disciplinares y tradiciones intelectuales, como: la geografía humanista, los estudios de ocio, el pensamiento de la filosofía clásica y el análisis del urbanismo deudor de la teoría crítica. Esta diversidad de referentes permitirá ofrecer una perspectiva más rica que pueda hacer justicia a la complejidad de fenómenos que convoca la cuestión de los espacios de ocio y su valoración, desde el punto de vista de su aportación al desarrollo humano.

Toda actividad humana es inherente a un momento del tiempo en que trascurre, así como a cierto espacio en el cual se lleve a cabo. El ocio remite a un determinado uso del tiempo. Así como en los seres vivos el paso del tiempo puede causar estragos en el cuerpo o la salud, también puede causarlos en un espacio natural, urbano, rural, o de cualquier tipo. El uso del tiempo no puede deslindarse de determinado uso del espacio. Dado que, en cuanto coordenadas abstractas de la acción humana, tiempo y espacio se encuentran en una relación directa:

\begin{abstract}
El tiempo se distingue, pero no se separa del espacio. Los anillos concéntricos en el tronco de un árbol revelan su edad, como también la muestran las espirales de los caparazones, "maravillosamente" concretas en el espacio, de acuerdo con leyes que solo complejas operaciones matemáticas pueden "traducir" el lenguaje de la abstracción. El tiempo, necesariamente, es local; eso conlleva relaciones entre los lugares y sus tiempos. Los fenómenos que la inteligencia analítica asocia exclusivamente con la "temporalidad" - a saber, el crecimiento, la maduración, el envejecimiento- no pueden en realidad ser disociados de la "espacialidad" (en sí misma una abstracción). El espacio y el tiempo aparecen y se manifiestan como diferentes e inseparables (Lefebvre, 2013, p.222).
\end{abstract}

Podemos observar que el espacio se distingue, pero no se desliga, del tiempo. Cuando el espacio es producido socialmente, adopta un sentido que le es dado en virtud del valor que le otorgue el hombre. Esto lo destaca como espacio, a la vez que, le brinda pautas para considerarlo un lugar. Es importante, entonces, ofrecer una distinción conceptual entre espacio y lugar:

\footnotetext{
El espacio es más abstracto que el lugar. Lo que comienza como espacio indiferenciado se convierte en lugar en la medida en que lo conocemos mejor y lo dotamos de valor. Si pensamos en el espacio como aquello que permite el movimiento, entonces el lugar es una pausa; cada pausa en el movimiento hace posible que la ubicación sea transformada en lugar (Smith, 2012, p.28).
}

El espacio es una abstracción de la que nace el concepto de lugar en medida de nuestra percepción. Incluso en las raíces mismas de la concepción física del espacio, Aristóteles en la Física se refería a este como un "lugar que en su totalidad es inmóvil" (1995, p.15-

\footnotetext{
1 Este artículo se enmarca en el proyecto del Plan Nacional de I+D+i PUBLICUM. Públicos en transformación. Nuevas formas de la experiencia del espectador y sus interacciones con la gestión museística (HAR2017-86103-P), Ministerio de Ciencia e Innovación del Gobierno de España.
} 
20). El lugar a diferencia del espacio, se presenta como una parte de este que se hace presente cuando el movimiento cesa. Entonces, el lugar implica una pausa. Es aquí donde el espacio se vincula con el ocio, en cuanto a actividad de pausa, contemplación y descanso.

El ocio es considerado actualmente por los especialistas en su estudio, como actividad libre, gratificante, desinteresada y sobre todo no utilitaria, que resulta benéfica para el individuo y la sociedad (Cuenca, 2009). Pese a que el ocio dependa estrechamente de cambiantes condiciones históricas, no ha dejado de estar fuertemente influido por su relación con las condiciones de trabajo. Inclusive cuando el ocio ha llegado a concebirse como ausencia de ocupación, ha tenido que ver con ella, precisamente, como su negación misma. Pero ¿qué podemos entender más ampliamente por ocio? Un concepto de ocio clásico dentro de los Estudios del Ocio, pero que sigue teniendo fuerte influencia hoy es el de Dumazedier: "ce contenu du temps orienté vers la réalisation de la personne comme fin dernière" 2 (1964, p.93). Un tiempo para la persona y su realización como finalidad corresponde a un ocio que ha de centrarse en el valor de las personas y el desarrollo de sus capacidades. Sin embargo, para poder comprender aún más el ocio y el sentido en que puede ser edificante para el desarrollo, es necesario distinguirlo de la común confusión que surge con él en relación al tiempo libre. El ocio como tal es un concepto que deviene de las raíces de la civilización occidental, del pensamiento de la antigua Grecia. En cambio, el tiempo libre es un concepto de la modernidad surgido en los inicios de la era industrial. Para aclarar más la diferencia entre ambos conceptos es conveniente acudir a la distinción que hace De Grazia:

\begin{abstract}
Todo el mundo puede tener tiempo libre, y no todos pueden tener ocio. El tiempo libre es una idea de la democracia realizable; el ocio no es totalmente realizable, y, por tanto, es un ideal y no sólo una idea. El tiempo libre se refiere a una forma determinada de calcular una determinada clase de tiempo; el ocio es una forma de ser, una condición del hombre, que pocos desean y menos alcanzan (1966, p.XIX).
\end{abstract}

Entender el ocio como capacidad es una idea que procede de Aristóteles. En la Política da una fuerte relevancia a la capacidad de tener ocio y lo considera necesario para la felicidad y la virtud, y por tanto valioso por sí mismo y principio de todas las cosas: "la naturaleza misma procura no solo el trabajo adecuado sino también estar en capacidad de tener un ocio decoroso, el cual es, para decirlo de nuevo, el principio de todas las cosas" (Aristóteles, 2000, p.302). Aristóteles mantenía un ideal en la relación entre ocio y trabajo: "trabajamos para tener ocio"; dicho de modo aún más gráfico (y más fiel al original griego): "estamos no ociosos para tener ocio" (Aristóteles, 1985, p.77). El ocio por definición tiene que ver con la liberación de la ocupación, como ya se ha dicho, pero también con el reposo, la calma y el descanso, que eran asociados con la contemplación y opuestos a la actividad (o, al menos, a ciertos tipos de actividad): "la raíz de skhole significaba, etimológicamente, parar o cesar; de aquí el tener reposo o paz. Más tarde significó tener tiempo desocupado o, específicamente, tiempo para uno mismo" (De Grazia, 1966, p.2). El tener tiempo para sí mismo era ligado a la necesidad de orientarlo adecuadamente a través de actividades nobles que debían también tener un sentido ligado al bien y a la virtud, así como a actividades que no estuviesen enfocadas a lo útil en sentido instrumental.

\footnotetext{
2 "El contenido del tiempo orientado hacia la realización de la persona como fin último" (tradcción de los
} autores). 
El ocio posee aún implicaciones que lo orientan a la realización y la felicidad, así como a la formación de la ciudadanía, por ello, conserva aún resquicios de su raíz que hacen indispensable destacar su valor. El ocio entonces deber ser considerado no como actividad residual, de enajenamiento derroche o mera reposición de fuerzas, sino como un ejercicio de libertad y virtud fuera de la ocupación. Fuera de los tiempos marcados por la actividad, y enfocada a la conciencia de un tiempo en el que el individuo se hace así mismo.

\section{EL VALOR DEL OCIO Y SU RELACIÓN SUS ESPACIOS}

En un sentido clásico, como ha tratado de explicarse hasta aquí, el ocio ha de ser comprendido y valorado como ámbito o vía que permite un pleno despliegue de las disposiciones naturales. Aristóteles entiende la esencia en cuanto fin o meta, que ligamos la idea del desarrollo: el ocio, por tanto, es aquí ante todo una vía de perfeccionamiento. La restricción aristotélica del ocio al colectivo de hombres libres (y, por tanto, la exclusión de esclavos, mujeres y niños) no debe impedir que rescatemos hoy el indudable potencial de su comprensión del ocio como actividad valiosa en sí misma, de autodespliegue, mejora y desarrollo necesario para todos. Aristóteles considera que el ocio es valioso, en tanto lo considera con valor en sí mismo por ser un fin imprescindible y necesario para una vida feliz.

La naturaleza misma procura no solo el trabajo adecuado sino también estar en capacidad de tener un ocio decoroso, el cual es, para decirlo de nuevo, el principio de todas las cosas. Siendo ambos necesarios, el ocio es, con todo, preferible al trabajo y tiene razón de fin, por lo cual hemos de investigar cómo hemos de emplear nuestro ocio... Pero el ocio parece encerrar en sí mismo el placer, la felicidad y la vida bienaventurada (Aristóteles, 2000, p.30-35).

¿Cómo podemos definir esa cualidad esencial del ocio de ser valioso en sí mismo? Para eso sería preciso primero dar a entender qué es un valor en sí mismo, entendido como fin, en distinción a un medio. Es decir, es necesario ahondar en la naturaleza del valor y en sus distinciones y puntos de encuentro relativos a lo intrínseco y lo extrínseco.

Lo intrínseco, hace referencia a un fin que es valioso por ser un fin por sí mismo. El valor intrínseco es el origen de las cualidades mismas del valor y los demás valores que puedan emanar de él: “. ...al valor propiamente dicho, al que apreciamos por él mismo, podríamos llamarlo valor intrínseco" (Villoro 2012, p.16). El valor intrínseco es una forma pura de valor. Se trata del valor que precede a todas las otras formas de valor, y que propicia otros valores.

Del valor intrínseco surge otro tipo de valor que vincula al objeto o situación con las condiciones externas a él mismo: "también llamamos valor, en el lenguaje ordinario, a todo aquello que produce, sirve o conduce a un valor intrínseco. A este valor en sentido amplio lo denominaremos extrínseco" (Ibídem, p.16). Tenemos entonces una distinción de valor entre lo intrínseco y lo extrínseco, que es análoga a una tendencia valorativa entre fines y medios. Lo intrínseco tiende a ser fin en sí mismo, mientras que lo extrínseco es medio para llegar a un fin determinado, es decir, que, "se conoce por su propiedad de propiciar la realización de otra situación" (Ibídem, p.17). En el caso de la valoración del ocio, que es concebido como fin, podemos observar que existe un vínculo moral con el trabajo, que es necesario para captar el valor de ambas actividades. Es necesario valorar 
el trabajo para poder dar valor al ocio. Sin embargo, tales actividades requieren de una distinción entre el valor que poseen en relación a su condición de medio o fin.

Es necesario concebir el ocio desde una valoración de igualdad y no de subordinación ante el trabajo: al reflexionar sobre el valor del ocio se busca en parte la justificación del mismo. En su valoración se encuentra el porqué es necesario, lo cual lo vincula directamente con el trabajo. Por ende, habremos de manejar el binomio ocio-trabajo como en un plano de necesidad mutua. El trabajo necesita ser dignificado, y esto es posible a través del ocio. Asimismo, un trabajo digno es acreedor de un ocio digno.

La valoración del espacio se encuentra estrechamente ligada a su producción y socialización relativa a las actividades que en él se lleven a cabo. En esa relación entre producción y socialización del espacio se oscila entre la extracción de recursos naturales y la contemplación del paisaje y contacto con el mismo:

\begin{abstract}
“...a mediados del siglo XVIII, el romanticismo europeo — y su actitud hacia la naturaleza — había encontrado en Estados Unidos seguidores en aquellas clases que — de manera crecientedisfrutaban del ocio. Así, en la valoración del entorno, se abrió una brecha cada vez mayor entre el granjero que luchaba con el territorio virgen y el caballero culto que lo apreciaba como paisaje" (Tuan, 2012, p.92).
\end{abstract}

Esta brecha relativa a los regímenes de acción sobre el espacio separa hoy al extractor de recursos naturales y al turista, ambos imbricados en actividades centrales al circuito contemporáneo de acumulación de capital. En la actualidad, el problema para dar valor al ocio y al espacio, radica en que son valorados en términos de mercancía. La falta de capacidad ante el ocio y la tendencia reduccionista a limitarlo a actividades alienantes, de consumismo, entretenimiento nocivo y adicciones, lo sitúa más en términos de una valoración mercantil e instrumental. Lo mismo sucede con la producción del espacio, del énfasis en otorgarle un valor utilitario y mercantil resulta que se anteponga el valor de cambio (cantidad) al valor de uso (cualidad), por decirlo en términos marxistas ${ }^{3}$. La ganancia que es posible producir con un determinado espacio es lo que ha de prescribir su valor. Se da entonces una reducción del valor del espacio a su rentabilidad.

Por otra parte, para examinar la valoración del ocio y sus espacios, es necesario acudir a su relación con el trabajo. El ocio suele ser una actividad inseparable del trabajo; no puede pensarse sin este. Tampoco el trabajo por sí mismo, puede ser valioso si carece del ocio. Hasta este punto, pareciera que estamos ante una situación contradictoria, pues hemos sido insistentes anteriormente con la crítica respecto a pensar el tiempo solamente como un recurso orientado a la producción y el consumo, entendido solamente en virtud del trabajo. Así como se ha observado en los conceptos que se han analizado ya, trabajo, tiempo de trabajo, tiempo libre, estos como productores de valor (y en tal punto nos referimos al valor en su sentido mercantil). El problema de todo esto está en que el trabajo,

\footnotetext{
${ }^{3}$ Marx señala que toda mercancía posee valor de uso y valor de cambio. El valor de uso corresponde a las cualidades de los objetos, las cuales permiten satisfacer una necesidad. Por otra parte, el valor de cambio representa el valor mercantil, o bien el dinero que puede ganarse con la venta de tal objeto. En El capital, Marx matiza la distinción y relación entre ambos conceptos: "La utilidad de una cosa hace de ella un valor de uso. Pero esa utilidad no flota por los aires. Está condicionada por las propiedades del cuerpo de la mercancía, y no existe al margen de ellas. El valor de uso se efectiviza únicamente en el uso o el consumo. Los valores de uso constituyen el contenido material de la riqueza, sea cual sea la forma social de esta, El valor de cambio se presenta como relación cuantitativa, proporción en que se intercambian valores de uso de una clase por valores de uso de otra clase, una relación que se modifica constantemente según el tiempo y el lugar" (Marx, 2008, p.44-45).
} 
el tiempo, el espacio y la misma vida son reducidos a valoraciones mercantiles; no es solo que el tiempo, sea libre o no, este forzosamente concebido en virtud del trabajo, sino que el motivo de ello es que es visto como la producción de valor en un sentido instrumental para la acumulación de riquezas materiales:

\begin{abstract}
Nosotros partimos de un hecho económico, actual. El obrero es más pobre cuanta más riqueza produce, cuanto más crece su producción en potencia y en volumen. El trabajador se convierte en una mercancía tanto más barata cuantas más mercancías produce. La desvalorización del mundo humano crece en razón directa de la valorización del mundo de las cosas. El trabajo no sólo produce mercancías; se produce también a sí mismo y al obrero como mercancía, y justamente en la proporción en que produce mercancías en general (Marx, 2010, p.45).
\end{abstract}

La idea de Marx nos remite a la idea que se mencionó anteriormente. El tiempo, sea de trabajo, sea libre o de ocio, está reducido a usarse de manera instrumental como un productor de valor mercantil. Esto contribuye, siguiendo a Marx, a la desvalorización de lo humano, en tanto que el ocio y los espacios para él se convierten mercancía (así como en el tiempo de trabajo el obrero produce mercancías y se produce a sí mismo como mercancía). En ese proceder instrumental de producción de valor que se ha mencionado, el ocio corre el riesgo de alienarse y en lugar de producirse a sí mismo, de tener un resquicio de emancipación para hacerse a sí mismo, termina por reproducir el proceso del tiempo de trabajo. De manera que, produce ganancia por medio del consumo, evade la posibilidad de realizarse a sí mismo y convierte su tiempo en mercancía, a la vez que a sí mismo. Es entonces que ese proceso de mercantilización influye en la valoración del ocio, y hace necesario preguntarse: ¿Qué es aquello que buscamos en el ocio, más allá de la evasión paliativa de la distracción del entretenimiento, no es acaso un hacerse a sí mismo lo que está de fondo? ¿Un tiempo para nosotros mismos no habría de edificarnos, reorientarnos, emanciparnos y realizarnos más que alienarnos o distraernos? "El ocio no es, por sí mismo, más portador de sentido existencial que el trabajo, y la cuestión es más bien cómo se vive el ocio" (Svendsen, 2006, p.43). Por lo tanto, el ocio adquiere sentido según cómo sea vivido, lo cual depende de la orientación que se le dé respecto al tipo de actividades y prácticas que en él se lleven a cabo.

Más allá de percibirlo como tiempo libre (que es libre solo en función del trabajo), hemos de considerar el ocio como un tiempo propio usado libremente a voluntad para la preservación de nuestra dignidad. Esto a través de actividades que involucren el descanso, el juego, la recreación, la diversión, y el desarrollo de nuestras capacidades. Es decir, el ocio debe entenderse como una experiencia dentro de un uso del tiempo a voluntad, un ejercicio de autonomía y libertad que se conjuga con el juego como un tiempo en el cual el individuo se recrea a sí mismo, más allá de una mera reposición de fuerza de trabajo (Cuenca, 2009).

Solo a los seres humanos les surge la necesidad de un tiempo para sí mismos, la necesidad del ocio. Esta emerge de: "la tensión, que se acrecienta con la racionalización y tecnificación del trabajo, además de acrecentar la fatiga, plantea paralelamente una mayor necesidad de diversión y tiempo privado, un tiempo para sí” (Cuenca, 2009, p.286). Durante el trabajo se nos expropia nuestro tiempo; lo vendemos para obtener una ganancia con la cual subsistir. El tiempo que nos resta ha de ser incluso más valioso por ser un tiempo destinado, no al imperativo de la obligación y la necesidad de la subsistencia y manutención, sino a nuestro gusto y realización: 
El ocio actual dominante a nivel global puede ser considerado, de un modo genérico, como un ocio de consumo. Un ocio predominantemente pasivo, en cuanto que unos lo disfrutan y son otros los que lo piensan y lo organizan; un ocio que forma parte de una importante industria cuyo objetivo es el rendimiento económico (Cuenca, 2009, p.86-87).

A partir de la segunda mitad del siglo XX hasta nuestros días, la libertad y el ocio se han constituido como fines del mercado. Incluso, más que fines, como meros medios de alienación y consumo, con algunas excepciones marginales. El problema de eso, estriba en la confusión sobre la diferencia, ya no muy marcada entre ocio y tiempo libre; diferencia que el consumo difumina aún más acaparando a ambos usos de tiempo. Para esclarecer tal diferencia y hacer frente a esta confusión, es preciso explicar mejor en qué consiste el ocio. Más que abordar sus raíces, hemos de señalar qué es lo que posee ese uso del tiempo; esa experiencia que implica el ocio que pueda argumentarse que es posible dotarla de un valor no mercantil al orientarla a actividades de contenidos no alienantes. Un ocio dirigido a la educación, a las artes, a la formación del ciudadano, a la convivencia, a la contemplación y el cuidado de sí refiere mucho más valor y dignificación al trabajo que un ocio solo enfocado al entretenimiento y el consumo de mercancías. Esto lo hemos visto por la preocupación sobre la formación de dicha capacidad de potenciar las posibilidades del ser humano para llevar a la realización lo mejor que hay en él. Para transitar por una experiencia y una vivencia de tal magnitud es necesario tener en cuenta que ésta se conforme de ciertos valores que enaltezcan al ser humano.

El ocio enaltece los valores por ser una experiencia que preserva la dignidad, por tratarse de una actividad cuyo fin último es la realización de la persona. Dicha dirección va orientada a la promoción de valores, del ejercicio de la libertad y el cultivo y desarrollo de las capacidades y virtudes de las personas. De manera que, es una experiencia dentro de un determinado tiempo, que favorece a la persona, la mejora, para sí misma y su comunidad. Por tanto, defender un ocio que promueve valores, un ocio humanista, ha de ser defender los valores de la persona, la dignidad y por ende uno de los que es condición de posibilidad del ocio mismo: la libertad.

El ocio brinda condiciones para la libertad, por ser condición de sí la elección, el ejercicio de la voluntad para emplear el tiempo en una actividad u otra. "El grado de libertad existente en una sociedad se evalúa también por la medida en que está dispuesta a cultivar cosas que no poseen un valor mercantil" (Weber, 1969, p.273). El ocio actual enlazado al consumo limita la libertad al mero acto de consumo y sus posibles opciones. Se vuelve entonces necesario el ocio como condición de posibilidad para la libertad y el hacerse a sí mismo, formarse como sujeto tanto en el sentido individual como social. Volcaremos en lo que sigue esta reflexión axiológica sobre la cuestión del espacio (y los espacios del ocio) y su producción social.

\section{LA VALORACIÓN MERCANTIL EN LA PRODUCCIÓN DEL ESPACIO: ELEMENTOS PARA SU CRÍTICA}

En la sociedad actual, la actividad de consumo es tan imperante que logra la expansión de los caracteres de la mercancía a cualquier objeto, sujeto, espacio o tiempo. Esto es, a casi cualquier aspecto de la realidad, tal expansión corresponde a la condición a la cual 
nombramos "mercantilización". En la mercantilización el espacio y el tiempo social se convierten en un dominio subordinado a la forma dinero.

Más allá de ser meros contenedores de relaciones sociales los espacios contribuyen a producir, según sus características, un determinado tipo de relación social. Lefebvre propone una crítica al capitalismo por su organización del espacio de forma instrumental, en la cual se producen y reproducen las relaciones de producción basadas en el valor de cambio. El capitalismo principalmente antepone el valor de cambio al valor de uso en la producción del espacio. Por ello, también, la producción del espacio en la mercantilización es producción de valor. En la producción del espacio, la mercantilización posibilita la imposición del valor de cambio al valor de uso. La tesis de Liebre nos invita a pensar posibles formas de uso del espacio en experiencias y vivencias que no impliquen necesariamente la mercantilización.

De cara a la mercantilización parece necesario para la producción del espacio promover la producción de un valor más allá del mercantil, con el fin de dar otro valor al espacio, uno que revalorice al sujeto y lo cotidiano en contraposición al valor de cambio. Esto daría condiciones de posibilidad para la promoción de nuevos tipos de relaciones sociales no necesariamente mediadas por la mercancía, sino por el diálogo. Principalmente, por medio de la convivialidad y la recreación, la expresión de la cultura y demás formas de edificación posibles en el ocio. Entonces, si pretendemos revalorar el espacio, es necesario preguntarnos cómo lo percibimos, y si de dicha percepción puede surgir una valoración más justa que la que se promueve en el capitalismo:

\begin{abstract}
¿Cuáles son nuestras visiones del entorno material, sea este natural o artificio humano? ¿Cómo lo percibimos, cómo lo estructuramos, cómo lo valoramos? ¿Cuáles han sido y cuáles son nuestros ideales con respecto al medio? ¿De qué modo la economía, los estilos de vida e incluso el marco físico afectan nuestras actitudes y valores hacia él? ¿Qué relación existe entre entorno y cosmovisión? (Yi Fu Tuan, 2007, p.9).
\end{abstract}

Tanto la percepción como la valoración del espacio están en comunión con el modo en que el espacio mismo se produce socialmente. El acto de producir un espacio se mantiene unido a la concepción y contexto determinado a un tiempo, a una época, es decir que el espacio y el tiempo son elementos que permanecen indisociables y estrechamente relacionados. En su aspecto social, el uso del tiempo es condicionado por el espíritu de la época que determina también las relaciones sociales suscitadas en espacios destinados a contenerlas y a producir una relación social. De ahí que, el espacio social producido se instaura bajo la influencia de su tiempo: "el espacio y el tiempo aparecen y se manifiestan como diferentes e inseparables" (Lefebvre, 2013, p.222).

De acuerdo a la afirmación de Lefebvre, los caracteres del tiempo y el espacio en su forma más abstracta se hacen notar también en su producción social. En una era donde el consumo es casi imprescindible para la subsistencia y media prácticamente toda actividad humana, la actividad de consumo subordina al uso del tiempo y el espacio. El consumo remitido a los espacios torna la mercancía en un mecanismo de abolición y supresión, pero también de creación de espacios geográficos en aras de la circulación de mercancías y su consumo:

Al ser un subproducto de la circulación de mercancías, la circulación humana considerada como consumo, el turismo, remite fundamentalmente al ocio que consiste en visitar aquello que se ha vuelto banal. La ordenación económica de la frecuentación de lugares diferentes es ya, por sí sola, 
la garantía de su equivalencia. La modernización no ha extinguido únicamente el tiempo de los viajes, les ha hurtado también la realidad del espacio (Debord, 2012, p.144).

También los espacios de consumo en su formación remiten a una movilización que adquiere asimismo un valor de cambio, ya sea en cualidad de bien o servicio dirigido a la ocupación del tiempo de ocio. Este se convierte en una mercancía y se acondiciona en medida en que pueda convertirse en un espacio de consumo, lo cual implica que esto es ya una relación social, a saber, una relación social mediada por el consumo.

No obstante, el consumo se desarrolla como elemento de transformación y producción del espacio en un sentido mercantil en el que el capitalismo pretende la integración del espacio geográfico, de las áreas naturales y urbanas. Dicha integración pretende poner a la naturaleza al servicio de la producción y el consumo. En primer lugar, mediante la extracción de recursos de las áreas naturales destinadas a la producción. En segundo lugar, mediante la inserción del turismo y la industria del ocio, la cultura y el entretenimiento, consumo:

Por esta producción del espacio nuevo, el espacio entero ha sido integrado al mercado y a la producción industrial a la vez que este espacio ha sido transformado...Así pues: integración al capitalismo de la agricultura y también de la ciudad histórica y extensión al espacio entero, comprendida la montaña y el mar, a través de la industria del ocio (Lefebvre, 1974, p.219).

Es entonces cuando el espacio se torna lugar de lo cotidiano hecho mercancía, devenido valor de cambio en tanto espacio de consumo. De modo que estas implicaciones inciden en una estética del espacio; la cual podemos observar en los espacios urbanos, donde es evidente una socialización del espacio capitalista, que culmina en que "el espacio es un producto social y la ciudad es una obra" (Lefebvre, 2013, p.224). Estas críticas en torno al espacio, el tiempo y el consumo, exhiben las problemáticas actuales y formas de proceder. Por ejemplo, la dinámica de la gentrificación como una supuesta medida estética de los espacios urbanos consecuentes a la sociedad capitalista y los efectos del neoliberalismo y la globalización. Pues estos productos, ya sean espacio, tiempo o mercancía, siguen hoy en día estando sometidos a la lógica de la producción del espaciomercancía con sus caracteres de homogeneidad, fragmentación y jerarquización.

Los modos de producción del espacio social se observan en la ordenación del espacio que habitamos, esto es, del espacio urbano, y el modo en que este adquiere un valor de cambio según el lugar dónde se ubiquen. "El urbanismo es la conquista del entorno natural y humano por otra parte de un capitalismo que, al desarrollarse según la lógica de la dominación absoluta, puede y debe ahora reconstruir la totalidad del espacio" (Debord 2012, p.145). La ordenación del espacio y la estetización se basa en su capacidad para adquirir valor. En este caso, para adquirir valor de cambio. En relación al espacio y su producción, el valor que impera en él es el valor de cambio. Este es definido por otros valores que el espacio puede poseer como el valor estético e incluso a su valor histórico. Así pues, también podemos observar que el valor de cambio de un espacio producido es determinado en gran medida por su valor estético.

La ordenación del territorio y la dispersión espacial, que por sí mismas dan lugar a una mentalidad limitada y asimismo fragmentaria, tiene su origen en el hecho de que la propiedad privada de la tierra y la compra y venta del espacio como mercancía, se den en un movimiento de producción del espacio en la sociedad capitalista: 
[...] los momentos de reorganización parcial del tejido urbano se polarizan provisionalmente en torno a esas "industrias de la distribución" que son los supermarkets gigantescos, edificados en descampados sobre un pedestal de parkings; y estos templos del consumo acelerado están ellos mismos en fuga permanente, incluidos en el movimiento centrífugo que les desplaza a medida que se convierten a su vez en centros secundarios sobrecargados, pues han provocado una recomposición parcial de la aglomeración. Pero la organización técnica del consumo no es más que el primer nivel de la disolución generalizada que ha llevado a la ciudad a consumirse a sí misma (Debord, 2012, p.147).

Un ejemplo muy contemporáneo de la producción del espacio en relación al consumo son los centros comerciales, producidos a manera de espacios destinados a las actividades de ocio y consumo. Por centros comerciales entendemos los espacios producidos en la periferia urbana, a los cuales popularmente también se les ha llamado malls. El término "centro comercial" en castellano resulta aún incompleto para definir lo que es un mall. Pues la referencia de "centro" no coincide, en la mayoría de los casos con su localización en el contexto urbano, que más bien se sitúa en lugares periféricos y descentralizados. Además, éstos no sólo fungen de espacios contenedores de relaciones sociales respecto a actividades de consumo, sino que ofertan también tiempo en bloques consumibles. El consumo se convierte en una suerte de justificación para ocupar el tiempo libre, lo cual lo un tiempo consumible, un tiempo-mercancía ofrecido a ciertas personas. Dado que el centro comercial cumple también la función de segregación social de los consumidores según su capacidad de adquisición:

Los espacios de compra se configuran cada vez más como espacios híbridos: tiempo libre, compras y sobre todo diversión, una diversión que ya no es, por cierto, fruto de lo que se ha contratado con el vendedor, sino de la capacidad de soñar con los ojos abiertos, de mirar las mercancías y gozar con su espectáculo (Sassatelli, 2012, p.218).

El centro comercial vino a fusionar las actividades de la compra y entretenimiento en el acto del consumo, donde ocio y consumo se vuelven actividades imprescindibles la una para la otra. Es decir que, se vinculan y se hacen inseparables en el momento en que el ocio es reducido al tiempo de consumo, en un mero pasar el tiempo de ocio ocupándolo en consumir. Al referirnos aquí a los centros comerciales, estamos refiriéndonos "en esencia a espacios de socialización del consumo" (Sassatelli, 2012, p.219). La producción del espacio social en este caso queda subordinada al uso del tiempo como tiempo de consumo Dicho tiempo no es otra cosa que ocupar en un espacio determinado y configurado para el consumo. En consecuencia, el espacio que se produce es contenedor de relaciones sociales que se encuentran mediadas por el consumo. Pese a la aparente contemporaneidad de estos centros comerciales, la realidad histórica de estos conversores del espacio-tiempo vivido en valor de cambio por medio de la ensoñación y el consumo debe reconocerse ya, como hacía Benjamin (2013), en los pasajes comerciales del París decimonónico. Desde entonces, el cultivo de la fantasmagoría del paseante/consumidor ha sido la principal estrategia de estos espacios a la hora de subordinar el ocio a la producción de valor de cambio. Su extensión global, desde las lunas de aquellos incipientes escaparates parisinos hasta el entramado actual de la comunicación publicitaria en todos sus medios y soportes, desarrolla a escala planetaria lo que no puede entenderse sino como un régimen de capitalismo seductivo (Cuenca, 2013).

El mecanismo de lo urbano es configurado según sus áreas y ubicación en zonas específicamente para el consumo. Al mismo tiempo las áreas de la producción o del 
trabajo, implican una dinamización en el flujo de las mercancías, condicionada por la administración del espacio mismo que contiene las áreas referentes a estas actividades. En virtud de la misma administración del espacio es posible el flujo, en este caso, flujo de mercancías que da lugar a la dinamización mencionada.

El espacio producido se considera un contexto o bien una especie de contenedor de relaciones sociales, porque el espacio suscita determinado tipo de relaciones, según el sentido o fin del espacio producido. Por lo tanto, el espacio se nos muestra no solo como un elemento que refleja las relaciones humanas, sino que también las produce, da un lugar a ellas, las contiene, las delimita, por lo cual las constituye.

Por medio de la industria del ocio el capitalismo se ha encargado de producir espacio para el consumo, que adquiere un determinado valor económico en relación a estos espacios, lo que lo hace objeto de deseo. Los espacios de consumo se vuelven deseables ya que se nos presentan bajo la forma de un tiempo deseable en un lugar propicio al descanso y las necesidades del consumo. Además, este se nos oferta en bloques de tiempo para ser consumido en ciertos espacios aparentemente agradables, bajo el supuesto de ser accesibles y estar al alcance de nuestras posibilidades. Ante esto, cabe destacar que según Lefebvre, el espacio ha sido siempre político, lo que deviene en un movimiento dialéctico entre "espacio dominante y espacio dominado" (Lefebvre 2013, p.221). El espacio se halla fragmentado por la propiedad privada, que influye en que cada espacio tiene su propio propietario. Esta fragmentación también se da en muchos casos por estrategia, ya sea estrategia del mercado, estrategia del Estado o bien, como decía Lefebvre, "de la energía", esto en alusión al caso del petróleo y la extracción de recursos naturales y energéticos.

Así que "las fuerzas productivas no pueden definirse únicamente por la producción de bienes o de cosas en el espacio. Se definen hoy como la producción del espacio" (Lefebvre 2013, p.225). Aquí Lefebvre propone una crítica al capitalismo por promover una concepción del espacio en sentido meramente mercantil, por el hecho de que el espacio es donde se producen y reproducen las relaciones de producción capitalista. De ello, surge entonces la necesidad de plantear alternativas de valor y relaciones acordes a los espacios. Por lo tanto, sería justo plantear una desmercantilización de los espacios para el ocio, esto como una contribución para revalorarlos a partir de su valor cultural, más allegado al valor en un sentido humanista. Por ello, para finalizar, expondremos algunas consideraciones en esta línea más propositiva.

\section{EL VALOR CULTURAL DE LOS ESPACIOS PARA EL OCIO}

Para pensar en el valor cultural de los espacios para el ocio sería prudente retomar la siguiente pregunta: "¿cuál es la naturaleza del valor que una comunidad otorga a las tradiciones que simbolizan su identidad cultural?" (Throsby, 2001, p.41). Esto presupone la cuestión en torno al criterio de valor respecto al espacio, del cual, podemos decir que su valor radica no sólo en la percepción que de este se tenga. Sino en los parámetros estéticos imperantes de dónde se encuentre dicho espacio en relación a sus cualidades visuales y simbólicas de significación para la comunidad. "Dicho punto de vista humanista del valor cultural resalta características universales, trascendentales, objetivas e incondicionales de la cultura y los objetos culturales... por ejemplo, el museo y la academia se convierten en los depositarios de este valor cultural elevado o de élite" (Ibídem, p.42). Eso implicaría una revalorización no solo en el sentido de depósitos de 
valor cultural, sino en el de contenedores de relaciones sociales que implican la producción de criterios de dicho valor, como pueden ser valoraciones estéticas hechas por un comisario o la expectación de quienes visitan el museo o la galería. Por otra parte, no solo tal tipo de recintos pueden albergar dicho valor cultural que se puede vincular al ocio. También las calles, plazas, parques y demás espacios públicos poseen un valor cultural, sobre todo histórico y estético, y son además espacios donde puede surgir el ocio de diversas formas. Por ejemplo, mediante el paseo, o bien a partir de la apropiación de dichos espacios con intervenciones de artes visuales, la instalación, el mural, la escultura, el arte urbano, o bien de artes escénicas, la danza, el teatro, el arte de performance.

Ahora bien, si el valor cultural de los espacios denota un tipo de valoración distinta al valor económico, éstas tienden aun así a relacionarse. Esto es, que también el valor estético o histórico de un espacio lo puede dotar de un mayor valor económico. "El capital cultural proporciona tanto valor cultural como económico; el capital ordinario solo proporciona valor económico" (Ibídem, p.58). Sin embargo, el sentido dado en virtud de esa valoración cultural poco tiene que ver con el modo de valoración económica. Así, el valor cultural de un espacio le sustrae en cierta medida de la utilidad mercantil: "en el mundo laboral totalitario no puede darse un espacio inutilizado, ni una superficie del suelo que no se utilice, ni un período de tiempo que no se aproveche..." (Pieper, 1979, p.68).

Pese a que los espacios para el ocio no escapan del todo a la mercantilización del valor económico, logran suscitar encuentros que no tienen como fin la mercantilización o el consumo. Por ejemplo, a partir de la expresión o expectación del arte en sus diversas representaciones. Así como a través de la contemplación, en el caso de la naturaleza o de zonas naturales protegidas o áreas arqueológicas, en el diálogo y convivencia con los otros en cualquiera que sea el espacio pese a que esto implica el consumo por la actividad del turismo, por mencionar algunos. "Valor y sentido no son inherentes a un orden espacial, sino que es preciso invocarlos...el contexto de prácticas específicas, la organización del espacio puede sin duda definir las relaciones entre personas, actividades, cosas y conceptos" (Harvey, 2012, p.241). En este orden de ideas es debido precisar las características del valor cultural aplicables a los espacios culturales:

\footnotetext{
Valor estético: busca las propiedades de belleza, armonía, forma y otras características de la obra como componente reconocido de su valor cultural. Tal vez haya elementos añadidos en la interpretación estética de ésta. Influidos por el estilo, la moda y el buen o mal gusto.

Valor espiritual: este valor se podría interpretar en un contexto religioso formal, de manera que la obra tenga una importancia cultural especial para los miembros de una fe religiosa, una tribu o cualquier otra agrupación cultural, o que tenga una base laica, haciendo referencia a cualidades interiores compartidas por todos los seres humanos. Los efectos beneficiosos aportados por el valor espiritual incluyen la comprensión, la ilustración y el conocimiento.
}

Valor social: la obra puede aportar una sensación de conexión con los demás, y contribuir a una comprensión de la naturaleza de la sociedad en la que vivimos y una sensación de identidad y lugar.

Valor histórico: un importante componente del valor cultural de una obra de arte pueden ser las conexiones históricas: cómo refleja las condiciones de vida que se daban en el momento en que fue creada, y cómo ilumina el presente proporcionando una sensación de continuidad con el pasado.

Valor simbólico: las obras de arte y otros objetos culturales son depositarios y proveedores de significado. Si la interpretación que un individuo hace de una obra de arte supone la extracción de un significado, entonces el valor simbólico abarca la naturaleza del significado aportado por la obra y su valor para el consumidor (Throsby, 2001, p.43). 
En el caso del valor espiritual, se entiende dentro de los espacios para el ocio edificante, los lugares de culto, espacios configurados a la actividad espiritual o religiosa representada simbólicamente en la práctica de una determinada fe, esto es, en los templos. "El culto tiene con respecto al tiempo un sentido semejante al que tiene el templo con el espacio" (Pieper, 1979, p.68). Por ejemplo, un templo religioso puede concebirse como un lugar distintivo de una cultura y a su vez en un espacio de reflexión, de introspección y espiritualidad, que pueden darse durante el ocio.

\begin{abstract}
El templo quiere decir que una determinada superficie se separa, acotándola, cercándola, deslindándola del resto del suelo y se transfiere a los dioses en propiedad, se la sustrae al aprovechamiento. Mediante el culto y gracias a él se separa también del tiempo aprovechado en la labor diaria de un período determinado, un espacio de tiempo limitado, y este tiempo, lo mismo que el espacio de la superficie del recinto del templo no se utiliza, queda sustraído de la utilización (Ibídem, p.68).
\end{abstract}

Al dar cuenta de que el espacio del templo se sustrae a la utilización mercantil es posible tomarlo en cuenta como espacio de ocio edificante con un valor cultural que no se subordina al valor económico. De igual modo, puede darse la misma situación con espacios destinados a albergar objetos culturales y artísticos, a saber, la galería y el museo.

Los ordenamientos simbólicos del espacio y del tiempo conforman un marco para la experiencia por el cual aprendemos quiénes y qué somos en la sociedad... La noción de sentido común según la cual hay un lugar y un tiempo para todo es trasladada al conjunto de prescripciones que reproducen el orden social, al asignar significados sociales a espacios y tiempos (Harvey, 2004, p.239).

La apropiación de los espacios a través de prácticas escénicas y visuales logra la posibilidad de dotar de valor cultural también a espacios comerciales o de consumo. Esto puede ser mediante la intervención artística, digamos en un centro comercial respecto a la composición visual de un cuadro de Rembrandt, interviniendo el espacio e involucrando a quienes ocupan el tiempo en las compras invitándoles a la visita de un museo donde se expone la pieza, a modo de promoción cultural (acción llevada a cabo en un centro comercial en Ámsterdam). Este tipo de prácticas espaciales, aquí identificadas en el entendido de ocio edificante, sería interesante pensar en concebirlas en virtud de lo que Lefebvre caracteriza en tres dimensiones como lo experimentado, lo percibido y lo imaginado.

Dicho medio de representación dota al espacio de valor cultural, como en el caso anteriormente comentado. Los espacios públicos tienen esta capacidad multifacética de ser abordados a modo de alternativa ante el consumo y la mercantilización que los amenaza y transforma continuamente: "la definición de un tiempo y un lugar para todo necesariamente cambia y constituye un nuevo marco para la promoción de nuevos tipos de relaciones sociales" (Ibídem, p.253).

Por lo tanto, hay que poner especial atención en el efecto que tiene la mercantilización sobre los espacios para el ocio, a través de la imposición del valor de cambio sobre el valor de uso en la producción del espacio. Esta es la principal tesis de Lefebvre al respecto, misma que nos posiciona en pensar formas de uso del espacio en experiencias y vivencias que no impliquen su mercantilización. Por ejemplo, la práctica de la deriva planteada por Debord desde la psicogeografia, que consiste en iniciar una caminata como un discurso peatonal no premeditado sino guiado por las emociones y recuerdos que el 
ambiente y la geografía del lugar nos provocan. Podría pensarse también lo planteado en cuanto al flâneur de Baudelaire, que según Benjamin se configura en el andar, el paseante y los paisajes, a través de la ocupación del tiempo y la reflexión del mismo: "la calle conduce al flâneur a un tiempo desaparecido. Para él todas las calles descienden... La embriaguez se apodera de quien ha caminado largo tiempo por las calles sin ninguna meta" (Benjamín, 2013, p.422).

Así, la deriva desde la psicogeografía y el flâneur sirven como paradigmas alternativos del ocio, que constituyen la búsqueda y construcción de situaciones a partir de las relaciones que se establecen con y en el espacio, el camino, el paisaje, el deseo de ellos, la manera en que se aprehenden y las emociones suscitadas, nostalgia, tristeza, tranquilidad, etc. En resumen, las prácticas mencionadas pretenden dar otro valor al espacio, uno que no mercantiliza, un valor muy subjetivo y cotidiano en contraposición al valor de cambio.

\section{REFLEXIÓN FINAL}

La acción de repensar el valor y producción del espacio, supone la promoción de nuevos tipos de relaciones sociales no necesariamente mediadas por la mercancía, sino por el diálogo, la convivencia, la expresión de la cultura y demás formas de edificación. Puesto que la sociedad de consumo, en gran medida sugiere que nos encontramos en una sociedad ociosa, en la cual resulta también imprescindible reivindicar el ocio y su valor.

Dar valor al ocio, consecuentemente, lleva a valorar el espacio donde este se lleva a cabo. De igual forma, el valor del ocio no radica en la utilidad sino en las intenciones, en concreto en el modo en que lo orientamos se torna valioso. Por ese motivo, el valor del ocio se asocia al valor de las personas. Su espacio tiene un valor más allá de su coste en beneficio, producción y consumo en sentido mercantil. Ese valor que vincula a las personas, entre el diálogo y la comunidad, la convivialidad y la recreación es lo que lo vincula con el mismo valor del ocio. En esa óptica, el desarrollo local viene a ser un factor importante no solo para la derrama económica y la extracción de recursos, sino sobre todo para la revaloración cultural e histórica de la localidad, tanto para su promoción como para la convivialidad entre sus pobladores y visitantes. Desde ahí puede imaginarse una alternativa en que el turismo y el ocio conjuguen esa valoración del espacio que excede el interés mercantil o bien lo toma como medio para un fin mayor, que oscila entre la preservación de bienes culturales, tanto tangibles como intangibles $\mathrm{y}$, el reconocimiento de las prácticas culturales y la apropiación de espacios públicos para la promoción de un auténtico desarrollo local.

\section{REFERENCIAS BIBLIOGRÁFICAS}

Aristóteles (1985). Ética Nicomáquea. Madrid: Gredos.

Aristóteles (1995). Física. Madrid: Gredos.

Aristóteles (2000). La politica. México: Editorial Porrúa.

Benjamin, W. (2013). Libro de los pasajes. Madrid: Editorial Akal. 
Cuenca, J. (2013). Peter Pan disecado. Mutaciones políticas de la edad. Bilbao: Consonni.

Cuenca, M. (2009). Ocio humanista. Bilbao: Universidad de Deusto.

De Grazia, S. (1966). Tiempo, trabajo y ocio. Madrid: Tecnos.

Debord, G. (2012). La sociedad del espectáculo. Valencia: PRE-TEXTOS.

Dumazedier, J. (1964). Hacia una civilización del ocio. Barcelona: Estela.

Harvey, D. (2004). La condición de la posmodernidad. Buenos Aires: Amorrortu.

Lefebvre, H. (1974). La producción del espacio. Papers: Revista de sociología, (3), 219229. http://dx.doi.org/10.5565/rev/papers/v3n0.880.

Lefebvre, H. (2013). La producción del espacio. Barcelona: Capitán swing.

Marx, K. (2008). El capital. Ciudad de México: Siglo XXI editores.

Marx, K. (2010). Manuscritos económico-filosóficos. Madrid: Alianza

Pieper, J. (1979). El ocio y la vida intelectual. Madrid: Rialp.

Sassatelli, R. (2012). Consumo, cultura y sociedad. Buenos Aires: Amorrortu editores.

Smith, J. Z. (1987). To take place: Toward Theory in Ritual. Chicago: The University of Chicago Press.

Svendsen, L. (2006). Filosofía del tedio. Barcelona: Tusquets.

Throsby, D. (2001). Economía y cultura. México: Gestión cultural.

Tuan, Y. F. (2007). Topofilia. España: Melusina.

Villoro, L. (2012). El valor y el poder. Ciudad de México: Fondo de Cultura Económica.

Weber, E. (1969). El problema del tiempo libre. Estudio antropológico y pedagógico. Madrid: Editora Nación. 